\title{
Estratégia\&Negócios
}

ISSN 1984-3372

http://www.portaldeperiodicos.unisul.br/index.php/EeN/

\section{ESTRATÉGIA DE PRODUÇÃO E SEU SUPORTE À COMPETIÇÃO: O CASO DA EMPRESA DELÍCIAS DO TRIGO NO MERCADO DE PANIFICADOS}

PRODUCTION STRATEGY AND YOUR SUPPORT FOR COMPETITION: THE CASE OF THE COMPANY'S DELÍCIAS DO TRIGO IN THE BAKERY MARKET

\section{Wellington Tavares}

Professor Assistente na Universidade Federal de Ouro Preto - UFOP. Doutorando em Administração pela Universidade Federal de Minas Gerais -UFMG.

E-mail: wellington@cead.ufop.br

\section{Cleber Carvalho de Castro}

Professor na Universidade Federal de Lavras - UFLA. Doutor pela em Agronegócios pela Universidade Federal do Rio Grande do Sul - UFRGS

E-mail: clebercastrouai@gmail.com

Recebido em 28/03/2012. Aprovado em 07/02/2013. Disponibilizado em 05/05/2013.

Avaliado pelo Sistema double blind review

R. eletr. estrat. neg., Florianópolis, v.6, n.1, p.26-53, jan./abr. 2013

http://portaldeperiodicos.unisul.br/index.php/EeN/index
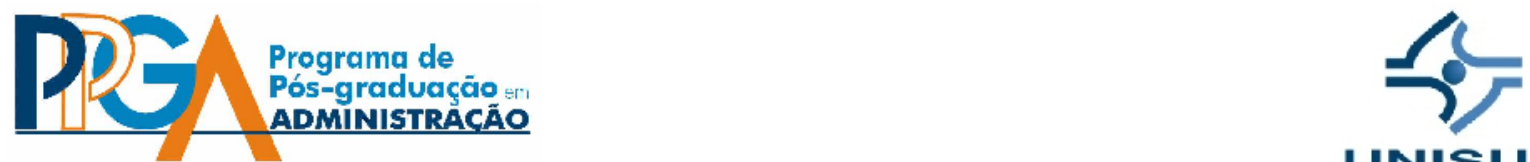

UNISUL

CCopyright 2008 UNISUL-PPGA/Estratégia e Negócios. Todos os direitos reservados. Permitida citação parcial, desde que identificada a fonte. Proibida a reprodução total. Em caso de dúvidas, consulte o editor:

ademar.unisul@gmail.com; (48) 3229-1932 


\section{RESUMO}

Atualmente, tem-se direcionado maior importância à área de produção, o que, em partes, se deve à maior convergência de opiniões sobre a importância da estratégia de produção e da competitividade. Nesse sentido, o presente artigo apresenta uma análise de como as estratégias de produção estão configuradas no setor de panificação. Com base nos estudos de Contador (1995) e Weelwright (1984), construiu-se um framework que foi utilizado para a análise das estratégias de produção no caso da empresa "Delícias do Trigo", identificando-se os campos em que a empresa compete (preço, produto, prazo, assistência ou imagem) e como ela atua nas categorias estratégicas de decisão (capacidade, instalação, tecnologia de processos, relação com os elos da cadeia, recursos humanos, qualidade e sistemas de organização e controle). Para as análises, utilizou-se, também, dos critérios qualificadores e ganhadores de pedido (HILL, 1992). Na coleta de dados do estudo de caso qualitativo, foi utilizada a entrevista semiestruturada. Entre as principais conclusões do estudo, pode-se ressaltar que apesar da expansão no atendimento, a empresa tem perseguido maior expansão por meio de novas contas de clientes e de aumentos nas vendas dos clientes atuais, inserindo novos produtos e linhas diferentes das que apresenta atualmente. Além disso, a empresa tem atuado de forma coerente no campo da qualidade do produto, o que permitiu um grande avanço em termos de organização da produção e de amadurecimento da ideia de negócio projetada nos anos anteriores à mudança no foco de atuação da empresa.

Palavras-chave: estratégia de produção. Critérios ganhadores e qualificadores de pedido. Competitividade.

\section{INTRODUÇÃO}

O processo de rápidas e profundas transformações, que vem ocorrendo no ambiente competitivo atual, tem exigido uma nova postura por parte das empresas que almejam manter ou melhorar suas posições no mercado. Nesse sentido, a busca de 
vantagens competitivas sustentáveis tem direcionado tempo e esforços dos executivos no intuito de vencer o desafiante jogo da competição. À medida que se acirra a competitividade nos diversos setores da economia, há um ganho importante para toda a sociedade, que se traduz, geralmente, em um melhor atendimento de seus desejos e necessidades por meio de produtos mais baratos e de melhor qualidade.

Diversas são as discussões sobre os processos mais adequados que possam permitir o alcance dos objetivos empresariais de forma mais eficaz. De um modo geral, há uma certa convergência de opiniões sobre a importância da estratégia empresarial (como catalisadora de esforços) e de seu suporte funcional fundamental: a estratégia de produção. No setor de panificação, assim como em outros setores, podem-se observar diversas ações das empresas que demandam um claro suporte por parte da estratégia de produção. Isso significa que as empresas precisam estar organizadas internamente de forma a atender às demandas do mercado.

Busca-se responder à seguinte questão de pesquisa: de que forma a estratégia de produção pode dar suporte para o alcance dos objetivos pretendidos pela estratégia de negócio global de uma empresa? O estudo busca responder à questão por meio de uma pesquisa em uma empresa de panificação, na qual a estratégia de produção pode se apresentar como uma das áreas mais relevantes para sua estratégia de negócios. Nesse sentido, o presente trabalho objetiva verificar, por meio de um Estudo de Caso, como as estratégias de produção estão configuradas no setor de panificação, dando, assim, suporte para a competição.

A partir daí, o estudo se justifica, teoricamente, em função do reduzido número de trabalhos que contemplam distintas variáveis do setor de produção e impactam a estratégia global de uma empresa no setor de panificação. Além disso, destaca-se a necessidade de se atentar para os aspectos produtivos que alteram, sobremaneira, a avaliação desse setor como forte ou fraco e sua relação com a capacidade competitiva no mercado. Para tanto, construiu-se um framework de análise das estratégias de produção que serviu de guia para todo o estudo, incorporando as contribuições de vários autores. Ao 
final, buscou-se realizar algumas inferências sobre o estágio de desenvolvimento das estratégias de produção da empresa.

O estudo justifica-se, empiricamente, uma vez que o mercado brasileiro de panificados apresenta grande potencial de expansão. O consumo de pão no Brasil, que em 2007 foi de $29 \mathrm{Kg}$ anuais per capita, está bem abaixo do consumo médio da Europa (60 Kg) e das recomendações da FAO (Food and Agriculture Organization), que são de 50 Kg anuais, e das recomendações da OMS (Organização Mundial da Saúde), que são de $60 \mathrm{Kg}$ anuais per capita (SINDIPAN-SP, 2009).

O texto está organizado em discussões teóricas, métodos, discussões empíricas e considerações finais. Na próxima seção, serão apresentados os principais conceitos em relação às estratégias de produção, passando pelos Campos da Competição e chegando nas Categorias Estratégicas de Decisão. Na terceira seção, serão abordados os elementos relacionados aos métodos e procedimentos utilizados no Estudo de Caso, com enfoque no esclarecimento sobre a utilização da entrevista e da visita técnica. Já na quarta seção, serão apresentados os principais achados do estudo empírico, bem como as discussões das informações encontradas. Por fim, na quinta seção, serão apresentadas as considerações finais do estudo e, posteriormente, as referências bibliográficas, na última seção.

\section{DISCUSSÃO TEÓRICA}

As transformações industriais, especialmente as ligadas às atividades de produção, mantêm uma estreita ligação com o desempenho das empresas em seus mercados, em especial, por meio das alterações de demandas. Para Masquietto et al. (2004), muitas empresas do setor de panificação têm encerrado suas atividades em função do não acompanhamento de mudanças estratégicas e competitivas ocorridas no setor, bem como pela baixa margem de retorno e altos custos. De acordo com a ABIP (dados de 2010 e 2011), a entrada de concorrentes mais agressivos no varejo alimentício tem exigido uma postura mais rígida das panificadoras em torno da qualidade, que é um requisito essencial para a 
obtenção de vantagens no mercado, que, por sua vez, podem ser buscadas por meio das estratégias de negócios e de produção.

O termo "estratégia", que atualmente se aplica a uma série de eventos cotidianos, foi cunhado pelos gregos com o significado de comando militar (GHEMAWAT, 2000). Contudo, o Planejamento Estratégico Empresarial que conhecemos hoje surgiu em meados da década de 1960, quando os negócios e as empresas começavam uma série de alterações visando a diversificar e expandir suas atuações (CAVALCANTI, 2001). Nota-se que, desde essa época, esse tipo de plano possibilitou aos gestores conhecerem suas estruturas e mercado, bem como se posicionarem frente às alterações sofridas ou que viriam a ser produzidas nas suas organizações, nas mais diferentes áreas.

Também na década de 1960, foram introduzidos os fundamentos da estratégia voltada para a produção, os quais futuramente viriam a abrir espaço para a implantação de técnicas e melhorias na manufatura (SILVA; SANTOS, 2005). Atualmente, compreende-se a estratégia de produção como aquela voltada especificamente para a manufatura, em consonância com a estratégia da empresa, como forma de tornar a competição pela produção uma prioridade, sendo baseada em programas de ação e políticas específicas (NOGUEIRA et al., 2001). De acordo com Hayes et al. (2005), a estratégia de produção é única para cada tipo de negócio, sendo que, mesmo em empresas com negócios variados, as estratégias de produção podem ter a necessidade de serem diversas e acompanharem cada um dos negócios.

Para Lustosa et al. (2008) o planejamento da produção deve projetar metas futuras, buscando otimizar recursos no atendimento às demandas. Para tal, torna-se necessário cuidar dos diversos elementos relacionados à produção, tais como: estoques, mão de obra, disponibilidade de materiais, padrões de produção e capacidade produtiva. Para Dotta (2009), além do impacto direto na competitividade de uma empresa de panificação, a área de produção é responsável por cuidados sanitários na manufatura que guardam estreita relação com a saúde dos seus clientes. Dessa forma, normas sanitárias de produção, tais como as Boas Práticas de Fabricação (BPFs), devem constar no planejamento da produção, visando à manutenção de um ambiente sanitariamente adequado. 
No entendimento de Pires et al. (2009), as panificadoras têm passado a encaminhar suas estratégias na direção em que o mercado tem apresentado suas demandas, mudando vários conceitos tradicionais e indo além da preocupação exclusiva com a produção. Nesse sentido, compreende-se a produção como elemento fundamental, e não diferenciador, muito importante na estratégia de negócios de uma empresa para a obtenção de vantagens competitivas em termos de qualidade e custos. Já na visão de Hitt et al. (2003), a vantagem competitiva de uma empresa surge quando ela gera algum valor que outras empresas têm dificuldade de imitar, ou mesmo quando é bem-sucedida na implantação de uma estratégia. No setor de panificação, por exemplo, a competitividade também tem sido buscada por meio da incorporação de serviços aliados aos produtos, conforme discussão apresentada por Martins (2000).

Historicamente, podia-se constatar a pouca importância que era dada para a área de produção e a sua desconexão com a estratégia global das empresas. Porém, desde o início da década de 1990, passou-se a requerer cada vez mais essa efetiva ligação como forma de atingir os objetivos estratégicos da organização. Uma maior ênfase passou a ser dada nos aspectos que permitem a integração das estratégias de manufatura ao planejamento estratégico global das empresas, que, além de despontar com um grau de relevância tão grande quanto os das demais áreas das organizações, reflete as alterações ambientais e influi consideravelmente na capacidade competitiva das empresas no mercado (ALBULQUERQUE; SILVA, 2002).

Muitas transformações foram ocorrendo na área de produção, na qual se pode destacar a introdução de novas tecnologias de produção baseadas em componentes eletrônicos, sistemas integrados por computador e sistemas de comunicação. Juntamente com essas mudanças, tem sido cada vez mais valorizada a flexibilidade dos sistemas de produção como forma de melhor atender ao mercado. Assim, a tecnologia de produção pode ser entendida como uma força direcionadora da estratégia global das empresas, podendo mudar atividades, abrir novos mercados, vincular novos clientes, criar novos canais de distribuição, novos métodos de vendas e até novas indústrias (HERRMANN, 2008). 
Tais transformações na produção apresentam ligações com suas estratégias e deferenciam os graus de desempenho entre as manufaturas das empresas. Ao inferir que essas diferenças guardam relações com as estratégias de manufatura adotadas, torna-se possível estabelecer comparações entre as empresas para compreender em que estágio de estratégia elas se encontram. Em relação aos estágios de desenvolvimento da estratégia de manufatura, Wheelwright e Hayes (1985) propuseram uma classificação em quatro estágios, destacando 3 pontos importantes: a) os estágios não são mutuamente excludentes; b) é quase impossível "pular" um estágio; e c) o real trabalho de desenvolvimento ocorre no nível da unidade de negócio. Os estágios, propostos pelos autores, podem ser assim resumidos:

a) Estágio 1: preocupação em minimizar o papel negativo da manufatura (“internamente neutra”). Neste estágio, consultores são chamados para a tomada de decisões estratégicas, há um forte sistema interno de controle do desempenho, a postura é eminentemente flexível e reativa e há um privilégio da tecnologia de produto e uma neutralidade em relação à tecnologia de processo.

b) Estágio 2: preocupação em minimizar o papel negativo da manufatura ("externamente neutra"). Uma empresa que está neste estágio, pode ser seguidora da "prática industrial", ter horizonte de planejamento de apenas um ciclo de negócios, ter o investimento de capital como meio principal para competir, evitar mudanças que trazem descontinuidade e obter eficiência por meio da economia de escala.

c) Estágio 3: neste estágio a empresa já suporta a estratégia de negócio, investe de forma consistente com essa estratégia, há uma formulação e busca da estratégia de negócio, os planos se desenvolvem em longos prazos (com as devidas revisões) e os gerentes tipicamente suportam, mas não formulam estratégia.

d) Estágio 4: representa o estágio mais avançado, onde há um suporte externo das estratégias de produção. Neste estágio as empresas buscam se antecipar aos avanços tecnológicos e de práticas de produção. É neste estágio que é 
proporcionado o maior retorno em termos de sucesso competitivo para a empresa.

Hill (1992), relacionando as estratégias de marketing com as de produção, define critérios qualificadores e ganhadores de pedido. Basicamente, os qualificadores são aqueles considerados básicos, que qualificam a empresa a entrar ou permanecer no mercado. Os critérios ganhadores de pedido são os que definem a venda, quando comparados com a concorrência. Esses dois conceitos são de grande importância para o entendimento dos efeitos das decisões estratégicas de produção no ambiente competitivo em que as empresas estão inseridas, e à agregação de valor aos produtos que as capacitam competitivamente (AREND; BROMILEY, 2009).

No intuito de verificar os aspectos relativos às estratégias de produção da empresa em questão, buscou-se conhecer os campos em que a empresa compete e sua posição em relação às categorias estratégicas de decisão.

\subsection{CAMPOS DA COMPETIÇÃO}

Contador (1995), com o objetivo de diferenciar as estratégias que a empresa adota para o alcance da vantagem competitiva, define a escolha de campos e armas da competição. Os campos da competição são aquelas áreas em que a empresa pode atuar e que o comprador é capaz de perceber. O que importa para o comprador, por exemplo, é o preço baixo e a qualidade do produto ou serviço que ele está adquirindo, e não o nível de produtividade alcançado pela empresa ou o índice de perdas na indústria. Conforme define o autor, uma arma pode servir para competir em mais de um campo, da mesma forma que para a competição em um campo são necessárias várias armas. Para os objetivos deste trabalho, torna-se importante a definição dos campos genéricos da competição (Quadro 1). 
Quadro 1 - Campos genéricos da competição

\begin{tabular}{|ll|}
\hline \multirow{2}{*}{ Competição em preço } & 1. em preço; \\
& 2. em guerra de preço; \\
& 3. em promoção. \\
\hline \multirow{3}{*}{ Competição em produto } & 4. em projeto; \\
& 5. em qualidade; \\
& 6. em variedade de modelos; \\
& 7. em novos modelos. \\
\hline \multirow{3}{*}{ Competição em prazo } & 8. de cotação e negociação; \\
& 9. de entrega; \\
& 10. de pagamento. \\
\hline \multirow{3}{*}{ Competição em assistência } & 11. antes da venda; \\
& 12. durante a venda; \\
& 13. após a venda. \\
\hline \multirow{2}{*}{ Competição em imagem } & 14. imagem do produto, da marca e da empresa; \\
Fonte: & 15. preservação ambiental.
\end{tabular}

Fonte: Elaborado com base em Contador (1995).

Dependendo do setor em que a empresa está inserida, alguns campos são mais valorizados e outros são mais difíceis de encontrar empresas atuando, o que não significa que sejam menos importantes para sempre (HERRMANN, 2008). Enquanto em épocas anteriores as empresas não se preocupavam com a preservação ambiental, hoje é crescente o número de empresas que buscam tecnologias limpas de processo (arma da competição) para competir nesse campo.

O fundamental é escolher os campos em que se vai competir (pois é praticamente impossível competir em todos eles) e utilizar as armas mais adequadas para sustentar tal decisão, atuando adequadamente nas categorias estratégicas de decisão, conforme serão apresentadas e discutidas na sequência.

\subsection{CATEGORIAS ESTRATÉGICAS DE DECISÃO}

Wheelwright (1984) classifica as decisões estratégicas da produção em estruturais e infraestruturais. As estruturais são aquelas que possuem impacto em longo prazo e são difíceis de reverter, exigindo altos investimentos para se alterar, como capacidade, instalações, tecnologia e integração vertical. As infraestruturais são aquelas que possuem ligação com os aspectos operacionais do negócio e não requerem grandes 
investimentos em um determinado período de tempo, tais como força de trabalho, qualidade, planejamento e controle da produção e organização. As categorias estratégicas de decisão são, assim, os espaços em que as empresas atuam para dar suporte aos campos da competição. Uma sintonia entre a organização desses espaços e os campos em que a empresa compete pode gerar a vantagem competitiva para a empresa.

A partir do reconhecimento das categorias estratégicas de decisão e sua relevância para a compreensão das escolhas estratégicas da produção, buscou-se compreender os direcionamentos e implementações estratégicas na produção de uma empresa do setor de panificação, conforme se verá adiante. Contudo, para melhor compreensão do caso a ser apresentado, na próxima seção serão apresentadas as principais considerações acerca dos métodos e procedimentos nos quais se baseou o estudo.

\section{MÉTODO E PROCEDIMENTOS}

Para a análise das estratégias de produção no setor de panificação, foi utilizada a categoria de pesquisa qualitativa denominada Estudo de Caso. A abordagem qualitativa, difundida inicialmente pelos antropólogos, foi escolhida por permitir maior grau de flexibilidade à pesquisa. No estudo de caso qualitativo, onde não há hipóteses e esquemas de inquisição preestabelecidos, permite-se a decisão intencional na escolha do caso a ser analisado, considerando uma série de condições que possam ser facilitadoras para o foco da pesquisa (TRIVIÑOS, 1987; YIN, 2001).

Bogdan e Bilklen (1982) apontam que, entre as características básicas da pesquisa qualitativa, pode-se destacar o ambiente natural como fonte direta dos dados e o pesquisador com instrumento-chave. Além disso, a pesquisa qualitativa é descritiva, e as interpretações dos resultados surgem através da percepção de um fenômeno em um contexto, valorizando o processo de pesquisa, na qual as análises são feitas indutivamente e o significado é a preocupação essencial desta abordagem.

A escolha da empresa "Delícias do Trigo", localizada em Campo Belo (MG), se deve ao fato de ela estar obtendo grande inserção no mercado, apesar do pouco tempo de 
sua fundação, no ano de 1993, e do início da expansão das atividades de manufatura a partir do ano de 1998. Considerando a existência de poucas e fortes empresas atuando no setor de panificação, o desempenho obtido pela nova entrante tem chamado à atenção.

Para proceder às análises, foi construído um framework (Quadro 2) que balizou todo o processo de verificação de suas estratégias de produção. Conforme dito anteriormente, buscou-se incorporar a contribuição de vários autores, como Contador (1995), Platts e Gregory (1992) e Wheelwright (1984).

Quadro 2 - Framework de análise das estratégias de manufatura em uma empresa

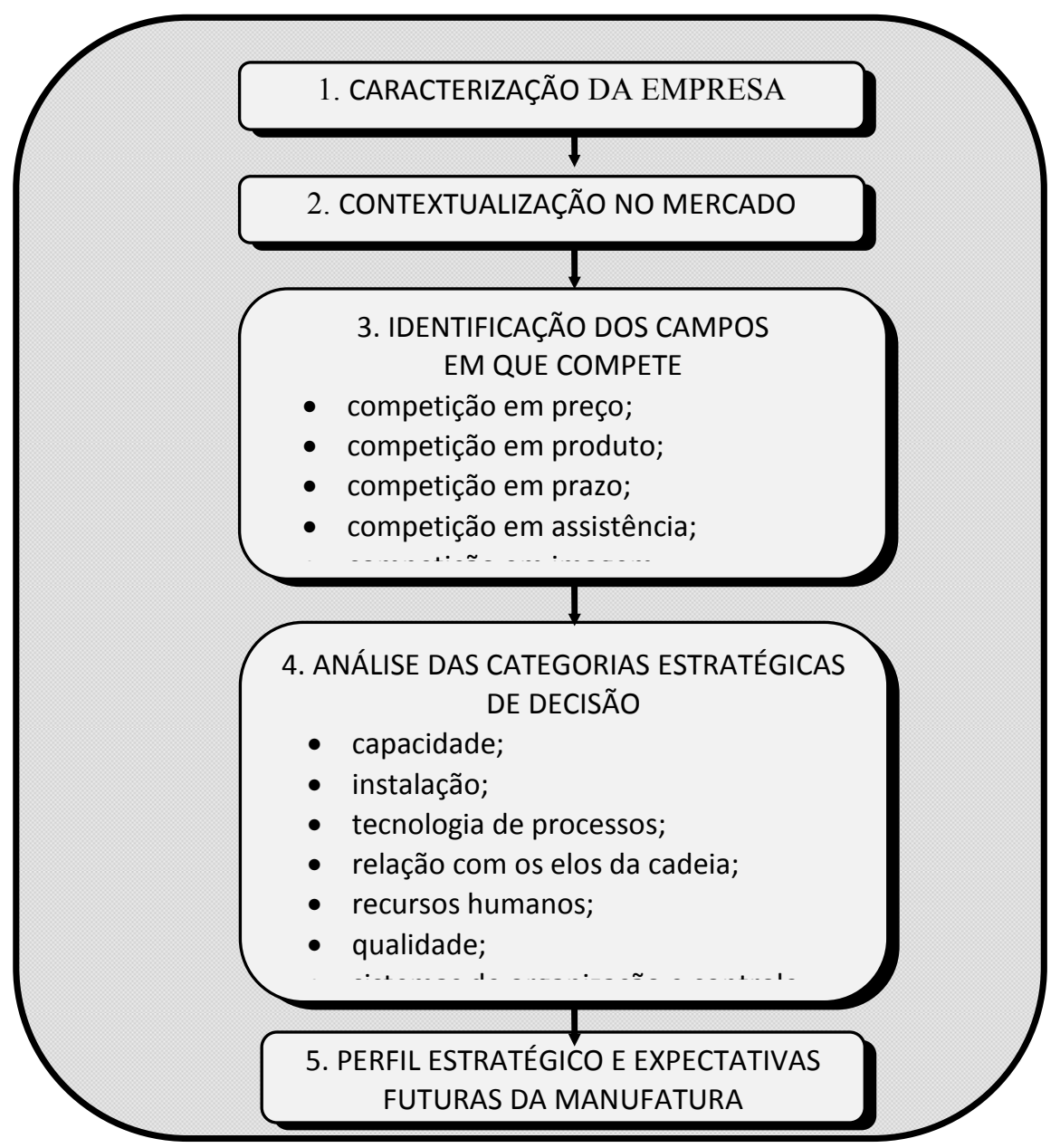

Fonte: Adaptado de Contador (1995), Platts e Gregory (1992) e Wheelwright (1984).

Na coleta de dados para o presente estudo não foi possível ter acesso a documentos como o Planejamento Estratégico da empresa, por exemplo. De acordo com o 
proprietário da empresa, existe um documento formalizado, mas ele, o proprietário, preferiu manter o sigilo das informações. Guardadas as restrições, outros meios e fontes de informações foram buscados para compor o estudo, visto que o enfoque deste trabalho é a estratégia específica aplicada à produção.

Utilizou-se de uma entrevista semiestruturada com o proprietário e administrador da empresa Delícias do Trigo. O estudo se baseou em apenas uma entrevista semiestruturada na empresa, visto que ela não apresentava outros indivíduos conhecedores das estratégias, sendo estas centralizadas na figura do único entrevistado. Esse tipo de entrevista foi escolhido por melhor se adaptar ao estudo qualitativo, valorizando a presença do entrevistador e proporcionando ao informante maior liberdade em suas manifestações.

No intuito de se obter uma maior riqueza na pesquisa, após a entrevista foi realizada uma visita técnica na fábrica para se constatar, in loco, as mudanças implementadas e conhecer a estrutura com a qual a manufatura conta hoje. Essa visita foi importante para atestar as informações da entrevista, já que esta havia sido a única fonte de informações encontradas na empresa, tendo sido restringidas outras fontes de informação.

Os principais resultados e discussões sobre as informações obtidas na pesquisa foram organizados e descritos na próxima seção, procurando estabelecer as ligações com os conceitos teóricos apresentados na seção anterior.

\section{RESULTADOS E DISCUSSÃO}

A empresa Delícias do Trigo foi criada no ano de 1993, quando a marca caracterizava apenas uma panificadora na cidade de Campo Belo, localizada na Região Sudoeste de Minas Gerais. Diante do crescimento obtido na cidade de Campo Belo (MG) e da percepção da oportunidade de expandir suas atividades para outras cidades da região, os proprietários buscaram expandir seus negócios, priorizando a produção e distribuição de panificação.

Atualmente, o Grupo Delícias do Trigo possui uma panificadora e uma fábrica, empregando 50 funcionários diretos, dos quais 36 são da área operacional, 4 do escritório e 
10 vendedores/motoristas. A produção envolve um mix de 15 produtos, distribuídos em 4 linhas, definidas como linha de pães, linha de biscoitos, linha de sequilhos e linha de pizza. Os produtos são estocados por no máximo 01 dia, quando são organizados em veículos próprios da empresa para a "pronta entrega", com exceção da linha de biscoitos, que, por possuir um período maior de validade, ficam estocados até 04 dias. A fábrica funciona 16 horas por dia para produzir seus 15 produtos, os quais, considerando os diversos tamanhos de embalagem, somam-se em 22 configurações diferentes, distribuídos em 4 linhas, conforme o Quadro 3.

A estratégia mercadológica atual da empresa tem foco diferente para o mercado mineiro e para o paulista. O mercado mineiro, normalmente, é atendido pela forma conhecida como "pronta entrega", para os vários produtos que oferta, enquanto que o mercado paulista é atendido por meio de pedidos, para a linha de biscoitos que apresenta um período de validade de até 90 dias.

Quadro 3 - Linha de produtos do Grupo Delícias do Trigo e sua participação no faturamento

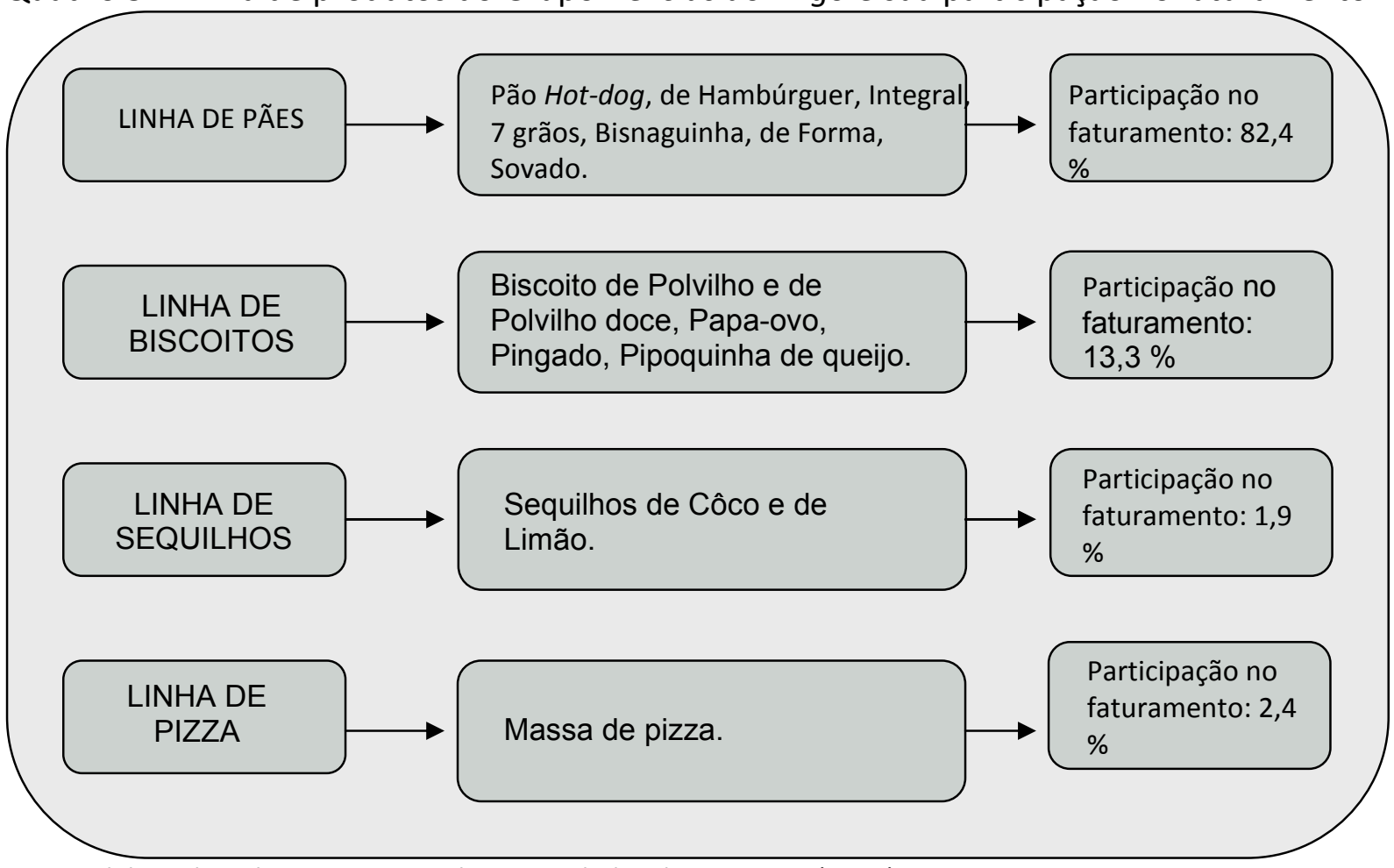

Fonte: Elaborado pelos autores com base nos dados da pesquisa, (2013). 
O entrevistado destacou como principal ponto forte da empresa o preço praticado, que é coerente com o que está estabelecido no mercado pelos seus concorrentes. Muitas vezes o preço praticado está abaixo dos concorrentes. Outro ponto citado se refere à distribuição dos produtos que, de acordo com a visão do entrevistado, consegue alcançar de forma eficiente os clientes e oferecer os produtos de maneira adequada, no prazo correto para reposição e com produtos ainda frescos, atendendo, desse modo, a grande solicitação dos clientes por produtos novos e de qualidade. Contudo, a empresa ainda pretende fazer alterações na estrutura utilizada a fim de otimizar mais os seus processos.

O principal ponto fraco da empresa é verificado na baixa utilização da capacidade instalada, em virtude do pequeno mercado que detém, em comparação com a capacidade dos maquinários instalados e da mão de obra disponível. Esse ponto se torna perceptível em razão da aquisição de equipamentos modernos que garantem uma grande produção, que vem a contrastar com uma demanda relativamente inferior à capacidade. Nesse caso, como se trata de produtos com período curto de validade, a empresa prefere subutilizar sua estrutura a ter que estocar produtos e correr risco de perdas.

A empresa atua em mais de 150 cidades de Minas Gerais, com foco em regiões como Sul, Zona da Mata, Campo das Vertentes e Centro-oeste, além de, atualmente, estar se inserido no mercado paulista, na região de Guarulhos (SP), onde estabeleceu uma distribuidora. Dos clientes atendidos, os supermercados respondem por $40 \%$ das vendas, as mercearias por outros 40\%, as padarias e os "sacolões" (mercados de hortifrutigranjeiros) respondem em igual proporção de $10 \%$ cada. Entre seus concorrentes, destacam-se marcas maiores, como a Seven Boys e demais marcas regionais, como New Bread (Poços de Caldas), Panolli (Bom Despacho), Campestre (Lavras), Vale D’ouro (Formiga) e Pães e Fadas (Pará de Minas), todas também já estabelecidas há um bom tempo no mercado mineiro, especialmente nas regiões em que a Delícias do Trigo atua. 


\subsection{IDENTIFICAÇÃO DOS CAMPOS EM QUE COMPETE}

A partir do reconhecimento da ligação das estratégias mercadológicas às estratégias de produção, seja como causa ou consequência desta, tornou-se necessário conhecer os campos nos quais a empresa compete para melhor compreensão posterior das estratégias de produção implementadas.

Basicamente, a empresa centra suas forças no campo da qualidade do produto e de forma subjacente em preço, buscando se tornar ganhadora de pedidos nesses dois campos. No campo da qualidade do produto, verificou-se que as decisões estratégicas têm dado suporte à essa competição, assim como à competição em preços. Outro fator bastante buscado em termos competitivos é a variedade dos produtos, a qual é mais bem trabalhada e verificada na linha de pães e biscoitos.

Em relação aos preços, verifica-se a utilização de uma série de promoções por parte da empresa para buscar a preferência de compra do consumidor em momentos específicos, tais como na abertura de novos pontos de venda e na melhoria das vendas de pontos que se encontram estáveis. Há uma grande preocupação da empresa em aumentar as vendas e a produção para se alcançar menores custos e, consequentemente, menores preços aos seus clientes, visto que boa parte dos recursos disponíveis estão sendo subutilizados. Há um controle dos custos internos (hora/máquina, hora/homem, matériasprimas, distribuição etc.), mas o aspecto mais crítico para manter um custo baixo encontrase nas muitas variações dos insumos utilizados na panificação, fugindo muitas vezes do controle que a empresa pode exercer.

Existe também uma preocupação da empresa em trabalhar melhor a questão do atendimento e assistência às vendas. Atualmente, é fornecida assistência ao ponto de venda na distribuição dos produtos por meio de frota própria, especialmente em "pronta entrega". A empresa verifica que muitos produtos, às vezes, não chegam no momento certo ao cliente, visto que ocorrem divergências nas demandas semanais/quinzenais que podem ocasionar a não existência do produto nas gôndolas quando procurados pelos clientes. Verifica-se claramente que existe um gargalo na distribuição, que a empresa pretende 
resolver por meio da terceirização das atividades de distribuição, estando, atualmente, estudando possíveis alternativas. Trabalha, ainda, na perspectiva de selar parcerias com distribuidores que já possuem um maduro conhecimento do mercado de panificados.

Além da qualidade física dos produtos e dos preços aos clientes, recentemente a empresa realizou algumas transformações estéticas em suas linhas de produtos, verificando a combinação de cores e rejuvenescimento da logomarca da empresa, para padronizar suas embalagens e permitir que os clientes identifiquem melhor os produtos da empresa, agregando valor aos produtos como fator relevante para o alcance de maior capacidade competitiva (AREND; BROMILEY, 2009). O trabalho de divulgação é de responsabilidade dos distribuidores em seus pontos de venda e nos prováveis clientes a serem conquistados. Além deste trabalho, por vezes se utiliza de estratégias baseadas na degustação dos produtos em alguns pontos de venda e na disponibilização de material gráfico em tais pontos. Agrega-se, ainda, as mídias utilizadas para divulgação a utilização de programas em TV local na região de Campo Belo (MG) e de um site atualizado da própria empresa.

A partir da compreensão das estratégias mercadológicas, é necessário recorrer às estratégias de produção que dão suporte para a estratégia de negócios da empresa, em especial, ao seu posicionamento no mercado e à sua condição competitiva. Dessa forma, na próxima subseção, serão realizadas as análises específicas sobre as estratégias de produção e suas relações com a estratégia de negócios da empresa.

\subsection{ANÁLISE DAS CATEGORIAS ESTRATÉGICAS DE DECISÃO}

De acordo com o framework anteriormente definido, será analisada, aqui, a posição da Delícias do Trigo em relação às categorias estratégicas de decisão na produção: capacidade, instalações, tecnologia de processos, estratégias de relação com elos da cadeia, recursos humanos, qualidade e sistemas (organização e controle). 


\section{a) Capacidade}

No intuito de vencer antigas dificuldades em relação à crescente demanda de seus produtos e poder melhor atender aos clientes, a empresa investiu recentemente na compra de um terreno ao lado da fábrica e construiu um novo espaço, que já é utilizado pela produção, além de servir para acondicionar estoques de matérias primas e de produtos acabados, quando necessário. Atualmente, a empresa tem um espaço físico construído de cerca de $1.800 \mathrm{~m}^{2}$, que não é utilizado em toda sua capacidade instalada para atender o mercado, o que apresenta pouco risco, já que se reduzem as dificuldades de se acompanhar o aumento da demanda (ADAM; SWAMIDASS, 1992).

A fábrica funciona em 06 dias da semana durante 16 horas diárias, nas quais a produção ocorre em 15 horas e o empacotamento, em 8 horas diárias. A ociosidade da estrutura pode ser utilizada para possíveis aumentos de demanda e a própria estrutura atual tem uma grande capacidade de se reconfigurar para atender novas demandas. Em termos de flexibilidade, seus equipamentos atuais servem todas as linhas de produtos, o que permite uma facilidade na mudança de mix de produtos. No entanto, o aumento na produção de uma determinada linha de produtos significa a diminuição de outra, já que existe um "colchão" de capacidade (FLEURY e PROENÇA, 1993). Existe, também, uma flexibilidade para lançamento de novas configurações do mesmo produto base, já que os processos são similares.

Devido à alta perecibilidade de praticamente todas as linhas de produtos (shelf life muito curto) e à estratégia da empresa de manter produtos sempre frescos nas gôndolas, não existe estoque de produtos acabados, apenas a formação de lotes para serem entregues rapidamente. Pode-se dizer que a competição em tempo é extremamente importante para essa produção e, hoje, pode ser considerada um critério qualificador.

\section{b) Instalações}

As instalações atuais da empresa são capazes de atender aos objetivos de aumento de market share, o que, inclusive, explica o fato de a empresa se utilizar de diversos veículos para divulgação de seus produtos. Os equipamentos utilizados são, em 
grande parte, formados por máquinas novas que demandam muito pouca preocupação com consertos e reparos. Assim, a manutenção acontece quando se torna necessária e a empresa ou profissional tem contratos estipulados por tempo determinado, apenas referentes ao trabalho específico para o qual se solicita o serviço. Apenas o setup, ou seja, a reconfiguração para produzir diferentes linhas de produto, é feito pelos próprios funcionários da produção.

\section{c) Tecnologia de Processos}

A tecnologia utilizada nos processos de produção é caracterizada pela constante incorporação de novas tecnologias de automação. Apesar disso, as atividades ainda demandam muito manuseio do produto, o que pode aumentar o número de produtos que são rejeitados pelo controle de qualidade. Em relação aos concorrentes, a tecnologia em uso está atualizada. O entrevistado justifica a equiparação de sua tecnologia ao afirmar que frequentemente há troca de informações com concorrentes por meio de interações diversas, em especial, por meio de visitas às fábricas que fazem entre eles, bem como na participação em feiras e eventos diversos do setor, procurando trazer melhorias ao desempenho da manufatura por meio de processos de comparação e de benchmarking (MÜLLER, 2003).

Apesar de ter maquinários novos e com grande capacidade produtiva, a Delícias do Trigo planeja novas aquisições de maquinários em curto prazo. Trata-se da aquisição, em especial, de novas máquinas para fatiar pães de forma, a fim de pulverizá-los contra mofo e embalar produtos de diferentes linhas. A aquisição da nova fatiadeira permitirá que se obtenha um menor tempo no processo de fatiamento dos produtos da linha "Pães de Forma", exigindo menor contato manual e maior qualidade. A nova pulverizadora anti-mofo terá a capacidade de evitar perdas no acondicionamento dos produtos da linha "Pães de Forma" e aumentar seu tempo de validade. A nova máquina embaladora permitirá que o processo referente à embalagem de alguns produtos demande menos contato manual, o que reduzirá as chances de erros e de perda de qualidade. 
A empresa mantém uma profissional da área química responsável pelas análises constantes de seus produtos, realizadas em laboratórios fora da empresa. Além disso, existe uma preocupação bastante considerável quanto aos aspectos nutricionais dos produtos, sendo que cada novo produto a ser lançado passa por avaliações nutricionais realizadas por profissionais contratados esporadicamente. Os testes para o lançamento de produtos novos são realizados dentro da própria fábrica e demandam uma média de 06 meses, excluído o tempo com pesquisa de mercado, para serem então incorporados no processo produtivo. A empresa mantém uma frequência de lançamento de novos produtos no período de um ano, sendo que para os próximos seis meses planeja o lançamento de três produtos de uma só vez, pois isso verifica a grande demanda de tais produtos e tem bastante relação com seu modelo de negócio.

\section{d) Relação com os Elos da Cadeia}

Atualmente, a empresa não tem serviços terceirizados, porém pretende terceirizar em partes a sua distribuição. Hoje, a empresa conta com frota própria para atender a seus clientes, somando o total de 13 veículos. Nesse processo, os motoristas dos veículos exercem, ainda, a atividade de vendedor e repositor nos pontos de venda, mas existe preocupação quanto à reestruturação de sua distribuição, tanto nas áreas em que a empresa já atua como em novas áreas. Para isso, iniciou esse processo implantando um Centro de Distribuição (CD) no estado de São Paulo, já que no estado de Minas Gerais a distribuição funciona na própria sede da empresa.

A empresa não mantém contratos formais de entrega de produtos por se tratar de um mercado com bastante variação na demanda. Os clientes são constantemente atendidos e têm seus cadastros atualizados periodicamente, com vistas a acompanhar as possibilidades de expansão das vendas. Além disso, existe uma preocupação da empresa em abrir novas contas de clientes nas regiões em que atua.

A relação com fornecedores, apesar de não ser caracterizada por contratos formais de entrega, apresenta um certo comprometimento destes em oferecer a qualidade exigida pela empresa. A empresa utiliza o grupo antigo de fornecedores, contudo, realiza 
cotações a cada compra, visando a tanto reduzir os custos das aquisições como também verificar se há disponibilidade dos produtos e se os prazos oferecidos condizem com a data de entrega requerida por ela.

Não se têm verificado casos de variações na oferta das matérias-primas da indústria nos tempos atuais, porém a empresa faz estoques que garantem a produção por cerca de um mês. Esse ponto é justificado pela empresa com o argumento, por exemplo, de que há reduções na oferta do polvilho em tempos de chuva, o que pode ocasionar em aumento nos preços, além de colocar em risco a produção e entrega dos seus produtos. A farinha de trigo, por exemplo, sofre alterações de preços de acordo com cotações do dólar, motivo pelo qual são feitos estoques maiores para assegurar os preços pelos quais se negociou em dados momentos.

\section{e) Política de Recursos Humanos}

Boa parte dos funcionários da produção são multifuncionais, possuindo habilidade para trabalhar em diversos postos com bom desempenho. $O$ treinamento existente é do tipo on the job, onde os funcionários mais experientes e de melhor desempenho auxiliam os novatos. A área de Recursos Humanos (RH) é considerada pela empresa como um gargalo para a melhoria do desempenho da qualidade e produtividade. Contudo, muitas ações foram verificadas nos últimos tempos, tais como a exigência do uso de uniformes no interior da fábrica, o uso de equipamentos de segurança do trabalho, a implantação de sistemas de reconhecimento dos funcionários, a manutenção dos salários equiparados aos do setor e aumento da participação dos funcionários, em termos de sugestões e na resolução de eventuais problemas. Outro ponto ressaltado sobre os avanços na área de RH é a parceria com planos de saúde e odontológicos, que oferecem aos funcionários a opção de contar com esses benefícios.

\section{f) Qualidade}

A empresa tem centrado bastante atenção no aspecto da qualidade. Existe um trabalho atual, focado no diagnóstico inicial das atividades da empresa, para a implantação 
de um programa de qualidade. Na empresa, já existe um acompanhamento diário da produção (planilhas de controle), onde é feito o controle das perdas por não conformidade, que, quando ocorrem, têm suas causas nas falhas de operacionalização da mão de obra ou da qualidade dos insumos. A qualidade é também assegurada pela atenção dada às exigências e recomendações de órgãos reguladores, como a Agência Nacional de Vigilância Sanitária (ANVISA) e a Vigilância Sanitária do município. O processo de verificação da qualidade é de responsabilidade de cada funcionário nas etapas em que trabalham, e no final do processo, os empacotadores realizam novas verificações nos produtos.

\section{g) Sistemas de Organização e Controle}

Embora não haja um planejamento estratégico formalizado, a empresa tem trabalhado no sentido de estabelecer um planejamento para os próximos anos. Há uma forte sintonia entre a direção da empresa e o gerente industrial, o que tem contribuído para a harmonia entre as decisões estratégicas empresariais e de produção. A integração das áreas da empresa e das diversas ações desempenhadas em relação à produção colabora para a maior capacidade da empresa, a fim de alcançar o desempenho objetivado em seu planejamento estratégico e melhores condições competitivas (SELLITTO, 2005).

Basicamente, a pesquisa de mercado realizada pela empresa é feita por meio dos vendedores/repositores de produtos, que trabalham abastecendo os clientes. São realizadas reuniões semanais ou quinzenais com eles, obterá fim de que a empresa obtenha o feedback das ações empreendidas. Além disso, a empresa mantém um telefone, e-mails e site para atendimento ao consumidor. Dessa forma, o sistema de organização e controle precisa estar bem ajustado para poder atender eficientemente os clientes, já que a empresa trabalha com produtos de shelf life muito curto. O planejamento da produção é feito diariamente, de acordo com os pedidos repassados pelos vendedores. 


\subsection{DISCUSSÕES}

Nesta análise, verificou-se uma posição de considerável conforto da estrutura da empresa em relação à demanda atual do mercado, e, de outro lado, notou-se a preocupação da empresa em expandir seu mercado, em razão do crescimento do setor de panificação e da estrutura que construiu, aumentando, assim, sua capacidade competitiva para aproveitar as oportunidades que possivelmente surgirão.

A busca por eficiência na produção é demonstrada diante da preocupação com a atualização dos equipamentos utilizados nos diversos processos, da busca por padronização e implantação de sistemas de qualidade e da adequação das condições estruturais como resposta às demandas. Já a busca por eficiência na distribuição e vendas é notada por meio das intenções de terceirização de atividades relacionadas ao transporte, da implantação de Centros de Distribuição em regiões estratégicas para seus negócios e da criação de novos formatos de distribuição que atendam às expectativas dos clientes quanto à qualidade, rapidez na entrega, variedade e baixos custos dos produtos.

Apesar da expansão do atendimento, conquistada em diversas regiões, a empresa ainda intenciona expandir o atendimento nessas regiões por meio de novas contas de clientes e de aumentos nas vendas dos clientes atuais, inserindo novos produtos e linhas diferentes das que são apresentadas atualmente. Além disso, pretende adentrar em novas regiões nos estados em que atua, bem como penetrar em algumas regiões do estado do Rio de Janeiro. Para tanto, a empresa está investindo em programas de qualidade, na formulação de novas estratégias e canais de marketing, na valorização dos funcionários e aperfeiçoamento de seus trabalhos, entre outros. A empresa definiu claramente que seu negócio é a panificação, não tendo intenção de diversificar para outros ramos, mas, sim, de lançar novas versões dos produtos ofertados e de linhas de produtos relacionadas às atuais.

Ao que tudo indica, a empresa tem atuado de forma coerente no campo da qualidade do produto ao se organizar em termos de estratégia para atuar sobre os elementos inibidores da qualidade. A estratégia, por exemplo, de automatização da fábrica, reflete a necessidade de diminuição do manuseio e aceleração do processo, o que leva a um 
potencial de melhoria da qualidade, ao aumento da produtividade e, de forma subjacente, à diminuição de custos. Devido à alta concorrência entre as empresas de panificação, há uma tendência de rápida transformação dos critérios ganhadores de pedido em qualificadores, exigindo da empresa uma postura proativa na descoberta de novas dimensões da competição.

Assim, pode-se inferir que a empresa esteja em um estágio de transição do estágio 2 para o 3, já que ela apresenta características desses dois. As características mais pronunciadas do estágio 2 são: decisão de um futuro investimento no crescimento da planta industrial e novos equipamentos, para se atualizar tecnologicamente em relação aos concorrentes, e busca de maior eficiência no processo atual como fator de aumento da economia de escala e, consequentemente, da produtividade. Nota-se, ainda, um certo movimento da empresa em busca de uma nova configuração, que está presente no estágio 3, convergindo para um certo direcionamento de esforços a fim de atingir um planejamento de mais longo prazo, sendo que os investimentos pretendidos já espelham uma estratégia de negócio (embora ainda não formalizada).

A fase atual da empresa representa um grande avanço em termos de organização da produção e de amadurecimento da ideia de negócio projetada nos anos anteriores à mudança no foco de atuação. Essa fase exige da gestão a preocupação em sintonizar os diferentes setores internos, com vistas a permitir um avanço maior da manufatura como forma de adequar-se aos novos patamares da competição do setor. Além disso, nota-se a existência de um processo de aprendizagem organizacional, focado na reorganização das diferentes áreas organizacionais para dar o devido apoio, juntamente com a produção, à estratégia maior da empresa.

A partir do esclarecimento dos principais resultados encontrados na discussão sobre o caso, torna-se necessário explicitar, na próxima seção, as principais considerações sobre o estudo como um todo, a partir do esclarecimento de questões relacionadas ao objetivo central do trabalho, suas contribuições e limitações, bem como sugestões para estudos futuros 


\section{CONSIDERAÇÕES FINAIS}

A partir das análises teóricas e práticas do estudo, foi possível compreender e demonstrar como a estratégica de produção de uma empresa pode dar suporte para o alcance das intenções estabelecidas na estratégia de negócio global de uma empresa. O trabalho se ancorou em um Estudo de Caso realizado em uma empresa de panificação, por meio de entrevista com o proprietário-gestor e visita à área de produção, na qual as estratégias produtivas da panificadora parecem ser os elementos de sustentação para a estratégia de negócios da empresa.

Em termos empíricos, o estudo colabora para o reconhecimento da realidade observada que, apesar de ser exclusiva da empresa analisada, pode dar bases para a gestão de demais empresas desse setor, bem como de setores correlatos, em virtude da clara exposição de aspectos ligados à cadeia de suprimentos, que englobam uma série de outros atores no setor de panificação. Além disso, outras empresas que tenham alterado suas estratégias de negócio, priorizando a área de produção, podem compreender a importância dessa área para o posicionamento estratégico que se assume, bem como sua relação com a competitividade e as estratégias globais de uma empresa. Ao evidenciar as alterações empreendidas pela empresa analisada, espera-se que o caso sirva de direcionador para a atuação de gestores.

Em termos teóricos, este trabalho possibilita o adensamento das discussões acerca da importância das estratégias de produção para as estratégias globais das empresas, bem como a compreensão de sua importância ao se realizar análises internas, necessárias nos processos de análise de posicionamento e definição de estratégias. Neste trabalho, os elementos retratados na área de produção da empresa analisada possibilitam refletir sobre como se formam as forças e fraquezas de uma organização e como elas impactam em sua capacidade competitiva frente às ameaças e oportunidades vislumbradas na análise externa à empresa: o mercado.

Algumas limitações se apresentaram para a realização do Estudo de Caso, o que, de certo modo, restringiu as possibilidades de generalização deste. Entre as principais 
limitações, estão o acesso a informações mais específicas e a restrição da entrevista a somente um ator organizacional, o proprietário-gestor. No estudo, foi possível realizar uma visita técnica na empresa como um todo, concentrando-se, posteriormente, na área da produção. Contudo, detalhes financeiros e de estratégias globais não foram disponibilizados para compor o estudo. Sobre a realização de apenas uma entrevista, isso se justifica pelas decisões que se concentram na figura do gestor e também pela não disponibilidade e liberação de funcionários para "falar" pela empresa.

A partir dessas limitações, sugere-se que novas pesquisas no campo de estudos da estratégia possam buscar outras variáveis estratégicas específicas que darão base para as estratégias de negócios globais das empresas, seja no setor de panificação ou em outros. Além disso, sugere-se que novos Estudos de Caso, nesse sentido, possam ser realizados, tendo outros instrumentos de análise, tais como Planejamentos Estratégicos formalizados, a fim de possibilitar o conhecimento das estratégias globais, e também alguns documentos financeiros, como os últimos balanços contábeis para observar o desempenho global após a implementação de estratégias.

\section{PRODUCTION STRATEGY AND YOUR SUPPORT FOR COMPETITION: THE CASE OF THE COMPANY'S DELÍCIAS DO TRIGO IN THE BAKERY MARKET}

\section{ABSTRACT}

Currently has been directed to the greater importance production area, which, in part, due to greater convergence of views on the importance of manufacturing strategy and competitiveness. In this sense, this paper presents an analysis of how production strategies are set in the baking sector. Based on studies of Contador (1995) and Weelwright (1984), we constructed a framework for analyzing production strategies through a Case Studies in the company "Delícias do Trigo", identifying the areas in which the company competes (price, product, period, service or image) and how it operates in strategic decision categories (capability, installation, process technology, compared with the links in the chain, human resources, quality and systems of organization and control). The analyzes were also used for 
qualifying criteria and winners order (HILL, 1992). In collecting data from qualitative case study was used semi-structured interview. Among the main conclusions can be noted that despite the expansion of services the company has pursued further expansion through new customer accounts and increased sales from current customers, entering new products and different lines from those presented today. In addition, the company has acted consistently in the field of product quality, which enabled a breakthrough in terms of organizing production and maturation of the business idea in previous years projected to change the focus of activity company.

Keywords: strategy production. Criteria winners and order qualifiers. Competitiveness.

\section{REFERÊNCIAS}

ADAM, E. E.; SWAMIDASS, P. M. Assessing in Operations Management from a Strategic Perspective. In: VOSS, C. Manufacturing Strategy: Process and Content. London: Chapman e Hall, 1992, p. 373-400.

ALBUQUERQUE, M. E. E.; SILVA, F. A. C da. Estratégia competitiva à estratégia de manufatura: uma abordagem teórica. Revista REad, São Paulo, n. 26, v. 8, n. 2, mar/abr, 2002.

AREND, R. J.; BROMILEY, P. Assessing the dynamic capabilities view: spare change, everyone? Strategic Organization, London, v.7, n.1, p. 75-90, feb., 2009.

ASSOCIAÇÃO BRASILEIRA DA INDÚSTRIA DE PANIFICAÇÃO E CONFEITARIA - ABIP. Performance do Setor de Panificação Brasileiro em 2010. Disponível em: <http://www.abip.org.br/perfil_internas.aspx?cod=102>. Acesso em: 19 jun. 2012.

ASSOCIAÇÃO BRASILEIRA DA INDÚSTRIA DE PANIFICAÇÃO E CONFEITARIA - ABIP. Performance do Setor de Panificação Brasileiro em 2011. Disponível em: <http://www.abip.org.br/perfil_internas.aspx?cod=199>. Acesso em: 19 jun. 2012.

BOGDAN, R. C.; BILKLEN, S. K. Qualitative Research for Education: An Introduction For To Theory And Methods. Boston: Allyn and Bacon, 1982.

CAVALCANTI, M. (org.). Gestão estratégica de negócios. São Paulo: Pioneira Thomson Learnig, 2001. 
CONTADOR, J. C. Campos da Competição. Revista de Administração, São Paulo (USP), v. 30, n. 1, p.32-41, jan./mar., 1995.

DOTTA, K.; LIMA, E. E. Avaliação das condições higiênico-sanitárias do setor de A\&B, de hotéis de uma cidade turística de litoral de Santa Catarina. Higiene Alimentar, São Paulo, v. 23, n. 176/177, p. 53-57, set./out., 2009.

FLEURY, P. F.; PROENÇA, A. Competitividade Industrial e a Gerência Estratégica de Operações. Revista de Administração, São Paulo (USP), v. 28, n. 2, p. 3-21, abr./jun. 1993. GHEMAWAT, P. A estratégia e o cenário dos negócios: texto e casos. Tradução Nivaldo Montingelli Jr. Porto Alegre: Bookman, 2000.

GRUPO DELÍCIAS DO TRIGO. Disponível em: <http://www.deliciasdotrigo.com.br>. Acesso em: 15 fev. 2012.

HAYES, R.; PISANO, G.; UPTON, D.; WHEELWRIGHT, A. Produção, estratégia e tecnologia: em busca da vantagem competitiva. Porto Alegre: Bookman, 2008.

HERRMANN, A. M. Contrasting the resource-based view and competitiveness theories: how pharmaceutical firms choose to compete in Germany, Italy and the UK. Strategic Organization, London, v.6, n.4, p. 343-374, nov., 2008.

HILL, T. J. Incorporating Manufacturing Perspectives in Corporate Strategy. In: VOSS, C. Manufacturing Strategy: Process and Content. London, Chapman e Hall, 1992, p. 3-11.

HITT, M. A.; IRELAND, R. D.; HOSKISSON, R. E. Administração Estratégica. São Paulo: Pioneira Thomson Learning, 2003, $550 \mathrm{p}$.

LUSTOSA, L.; MESQUITA, M. A.; QUELHAS, O.; OLIVEIRA, R. Planejamento e controle da produção. Rio de Janeiro: Elsevier, 2008.

MARTINS, W. A. Competitividade no setor de panificação: a busca de um novo modelo de gestão. Revista Administração em Diálogo, São Paulo, v. 2, n. 1, p. 1-16, edição anual, 2000.

MASQUIETTO, C. D.; SPERS, E. E.; CROCOMO, F. C.; ANTONIO, R. D. Competitividade no Segmento de Panificação do Município de Piracicaba. Revista de Administração da UNIMEP, Piracicaba, v. 2, n. 2, mai./ago., 2004.

MÜLLER, C. Modelo de gestão integrando planejamento estratégico, sistema de avaliação de desempenho e gerenciamento de processo. 2003. 292 p. Tese (Doutorado em Engenharia de Produção). Escola de Engenharia, UFRGS, Porto Alegre. 
NOGUEIRA, E.; ALVES FILHO, A. G.; TORKOMIAN, A. L. V. Empresas de revestimento cerâmico e suas estratégias competitivas e de produção. Gestão \& Produção, São Carlos, v. 8, n. 1, p. 84-99, abr., 2001.

PIRES, C. E. R.; SILVA, L. S.; FERREIRA, R. A. D.; MORAES FILHO, R. A. Estratégias no mercado panificador: a nova tendência delicatessen. Pretexto, Belo Horizonte, v. 10, n. 2, p. 43-58, abr./jun. 2009.

PLATTS, K. W.; GREGORY, M. J. A Manufacturing Audit Approach to Strategy Formulation. In: VOSS, C. Manufacturing Strategy: Process and Content. Chapman e Hall, 1992, p. 29-55.

SELLITTO, M. A.; Walter, C. Medição e pré-controle do desempenho de um plano de ações estratégicas em manufatura. Gestão e Produção, v. 12, n. 3, p. 443-458, set./dez., 2005.

SILVA, E. M.; SANTOS, F. C. A. Análise do alinhamento da estratégia de produção com a estratégia competitiva na indústria moveleira. Revista Produção, v. 15, n. 2, p. 286-299, mai./ago., 2005.

SINDIPAN-SP. Sindicato da Indústria de Panificação e Confeitaria de São Paulo. Disponível em: <http://sindipan.org.br/asp/consumoDePao.asp>. Acesso em: 24 fev., 2009.

TRIVIÑOS, A. N. S. Introdução a Pesquisa em Ciências Sociais: A pesquisa qualitativa em educação. São Paulo: Atlas, 1987.

YIN, Robert K. Estudo de caso: planejamento e métodos. Porto Alegre: Bookman, 2001.

WHEELWRIGHT, S. C. Manufacturing Strategy: Defining The Missing Link. Strategic Management Journal, San Diego, v. 5, n.1, p. 77-91, jan./mar., 1984.

WHEELWRIGHT, S. C.; HAYES, R. H. Competing Through Manufacturing. Harvard Business Review, New York, v.63, n.1, p. 99-109, jan./fev., 1985. 